\title{
Effect of Solid-Hydrogen Environment on UV-induced Hydrogen-Atom Transfer in Matrix-Isolated Heterocyclic Thione Compounds
}

\author{
Hanna Rostkowska, Anna Luchowska, Leszek Lapinski, and Maciej J. Nowak
}

Institute of Physics, Polish Academy of Sciences, Al. Lotnikow 32/46, 02-668 Warsaw, Poland

Supporting Information 


\section{Contents:}

\begin{tabular}{|c|c|c|}
\hline Figure S1 & $\begin{array}{l}\text { The comparison of the progress of the thione } \rightarrow \text { thiol } \\
\text { phototautomeric reaction in monomers of } 3 \text {-thiopyridazine } \\
\text { isolated in } \mathrm{Ar} \text { and } n-\mathrm{H}_{2} \text { matrices. }\end{array}$ & p. S3 \\
\hline Figure S2 & $\begin{array}{l}\text { The comparison of the progress of the thione } \rightarrow \text { thiol } \\
\text { phototautomeric reaction in monomers of 2-thioquinoline } \\
\text { isolated in } \mathrm{Ar} \text { and } \mathrm{n}-\mathrm{H}_{2} \text { matrices. }\end{array}$ & p. S4 \\
\hline Note S1 & $\begin{array}{l}\text { Remarks concerning the feasibility of reliable estimation of } \\
\text { quantum yield of phototransformations occurring in matrix- } \\
\text { isolated molecules. }\end{array}$ & p. S4 \\
\hline Figure S3 & $\begin{array}{l}\text { Thiol isomers of 3-thio-1,2,4-triazole generated upon } \\
\mathrm{UV}(\lambda>275 \mathrm{~nm}) \text { irradiation of the monomers of the compound, } \\
\text { isolated in Ar or } n-\mathrm{H}_{2} \text { matrices. }\end{array}$ & p. S5 \\
\hline Figure S4 & $\begin{array}{l}\text { Fragments of the IR spectra of 2-thioimidazole monomers } \\
\text { isolated in: } n-\mathrm{H}_{2} \text { and Ar matrices. The spectra are juxtaposed } \\
\text { with the theoretical spectrum calculated, at the DFT(B3LYP)/6- } \\
311++\mathrm{G}(2 \mathrm{~d}, \mathrm{p}) \text { level, for the thione tautomer of the compound. }\end{array}$ & p. S5 \\
\hline Table S1 & $\begin{array}{l}\text { Approximate assignment of the absorption bands, observed in } \\
\text { the IR spectrum of monomers of 2-thioimidazole isolated in Ar } \\
\text { and n- } \mathrm{H}_{2} \text { matrices, to the normal modes calculated, at the } \\
\text { DFT(B3LYP)/6-311++G( }(2 \mathrm{~d}, \mathrm{p}) \text { level of theory, for the thione } \\
\text { tautomer of the compound. }\end{array}$ & p. S6 \\
\hline Figure S5 & $\begin{array}{l}\text { Fragments of the IR spectra of } 2 \text {-thiobenzothiazole monomers } \\
\text { isolated in: } n-\mathrm{H}_{2} \text { and Ar matrices; juxtaposed with the } \\
\text { theoretical spectrum calculated, at the DFT(B3LYP)/6- } \\
311++\mathrm{G}(2 \mathrm{~d}, \mathrm{p}) \text { level, for the thione tautomer of the compound. }\end{array}$ & p. S7 \\
\hline Figure S6 & $\begin{array}{l}\text { The comparison of the progress of the thione } \rightarrow \text { thiol } \\
\text { phototautomeric reaction in monomers of } 2 \text {-thiobenzothiazole } \\
\text { isolated in } \mathrm{Ar} \text { and } \mathrm{n}-\mathrm{H}_{2} \text { matrices. }\end{array}$ & p. S7 \\
\hline Table S2 & $\begin{array}{l}\text { Approximate assignment of the absorption bands, observed in } \\
\text { the IR spectrum of monomers of } 2 \text {-thiobenzothiazole isolated in } \\
\text { Ar and n- } \mathrm{H}_{2} \text { matrices, to the normal modes calculated, at the } \\
\text { DFT(B3LYP)/6-311++G( }(2 \mathrm{~d}, \mathrm{p}) \text { level of theory, for the thione } \\
\text { tautomer of the compound. }\end{array}$ & p. S8-S9 \\
\hline Table S3 & $\begin{array}{l}\text { Structures of the tautomeric forms of the studied compounds } \\
\text { and the height of the barrier for the thione } \rightarrow \text { thiol, } \\
\text { oxo } \rightarrow \text { hydroxy or } \mathrm{N}(1) \mathrm{H} \rightarrow \mathrm{N}(7) \mathrm{H} \text { transformation, calculated at } \\
\text { the DFT(B3LYP)/6-311++G(2d,p) level and at the MP2/6- } \\
311++\mathrm{G}(2 \mathrm{~d}, \mathrm{p}) \text { level. }\end{array}$ & p. $\mathrm{S} 10-\mathrm{S} 11$ \\
\hline
\end{tabular}


The estimation of relative amounts of photoproduced thiol tautomers of the studied compounds isolated in an $\mathrm{Ar}$ and $\mathrm{H}_{2}$ matrices is not a straightforward task because the relative intensities of the corresponding absorption bands in the spectra of the monomers isolated in Ar and $\mathrm{H}_{2}$ matrices are usually different. Therefore we assumed that the amount of absorbing species in $\mathrm{Ar}$ and $\mathrm{H}_{2}$ matrices is proportional to the average intensity of several, most prominent absorption bands present in the spectrum. The average intensities were scaled in such a way that the average intensities of the bands due to molecules in thione form in the spectrum obtained before UV irradiation in $\mathrm{Ar}$ and $\mathrm{H}_{2}$ matrices are equal to 1 . Such procedure was applied for Figures S1, S2 and S6.

\section{3-thiopyridazine}

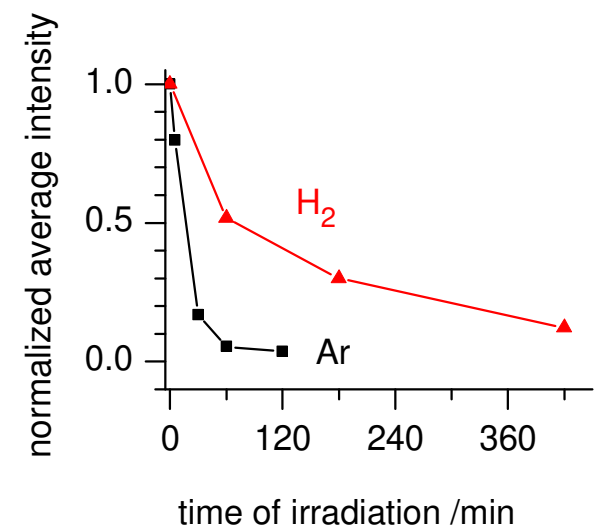

Decay of the thione tautomer during UV $(305 \mathrm{~nm})$ irradiation

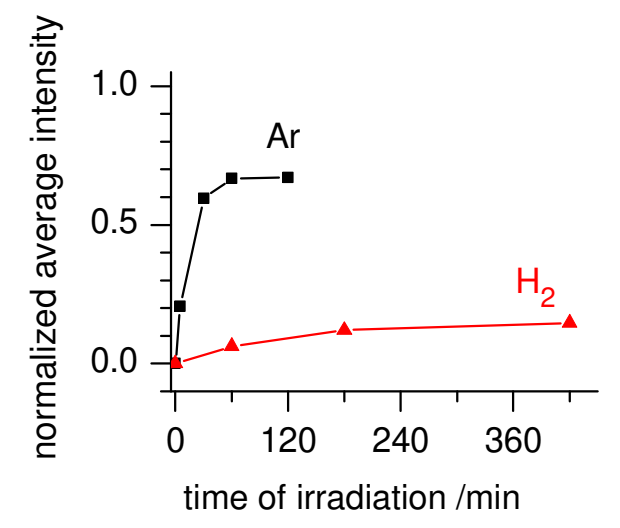

Formation of the thiol tautomer during UV (305 $\mathrm{nm})$ irradiation

Figure S1. The comparison of the progress of the thione $\rightarrow$ thiol phototautomeric reaction in monomers of 3-thiopyridazine isolated in $\mathrm{Ar}$ (black traces) and $\mathrm{n}-\mathrm{H}_{2}$ (red traces) matrices.

As it is usually the case, the average intensity of the IR bands in the spectrum of the thiol product was much smaller than the average intensity of the bands in the spectrum of the thione reactant. The absolute intensities of IR bands in the spectra of thiol forms are usually lower (as average) than the absolute intensities of the bands in the spectra of thione tautomers. 


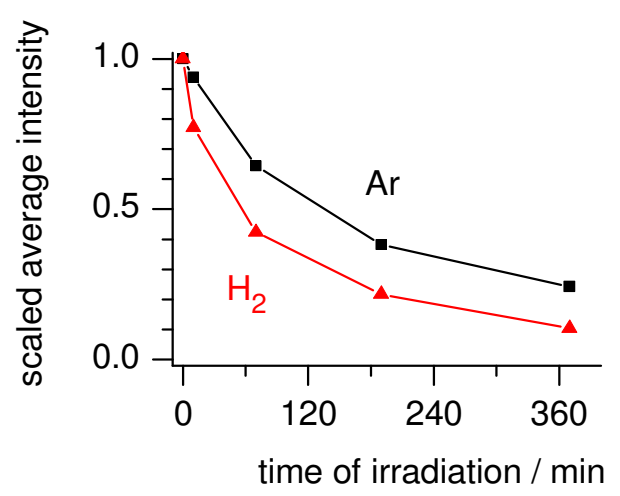

Decay of the thione tautomer during UV (305 nm) irradiation

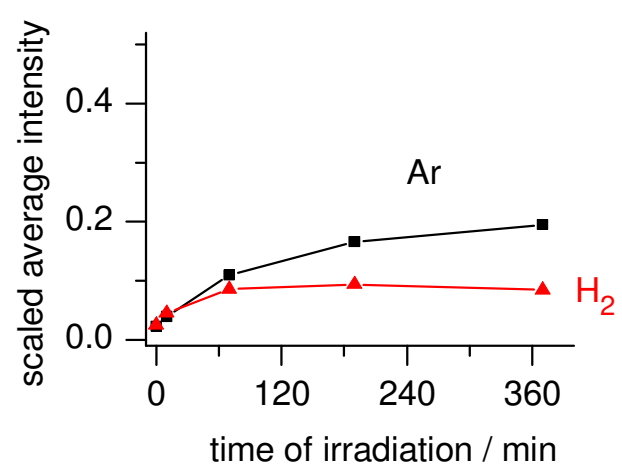

Formation of the thiol tautomer during UV (305 nm) irradiation

Figure S2. The comparison of the progress of the thione $\rightarrow$ thiol phototautomeric reaction in monomers of 2-thioquinoline isolated in $\mathrm{Ar}$ (black traces) and $\mathrm{n}-\mathrm{H}_{2}$ (red traces) matrices.

Note S1. Reliable measurement of quantum yields of light-induced processes occurring in matrix-isolated compounds is extremely difficult. That is why quantum yields of phototransformations of matrix-isolated species are extremely rarely measured. The reliability of the very few attempts carried out so far can be easily questioned. The reason for this is the fact that a low-temperature matrix is a very dispersive medium, especially for the UV light. Hence, the irradiation conditions of the molecules trapped in the layers closer to the surface are very different from the conditions of irradiation of the molecules trapped in deeper layers of the matrix. 
<smiles>Cn1ncnc1S</smiles>

form t11<smiles></smiles>

rotamers of form $\mathrm{tl} 2$

Figure S3. Thiol isomers of 3-thio-1,2,4-triazole generated upon UV $(\lambda>275 \mathrm{~nm})$ irradiation of the monomers of the compound, isolated in $\mathrm{Ar}$ or $\mathrm{n}-\mathrm{H}_{2}$ matrices. Colors of the structures correspond to the colors of the sticks in the bottom panel of Fig. 6, where fragments of the theoretically calculated IR spectra of the three isomers are presented.

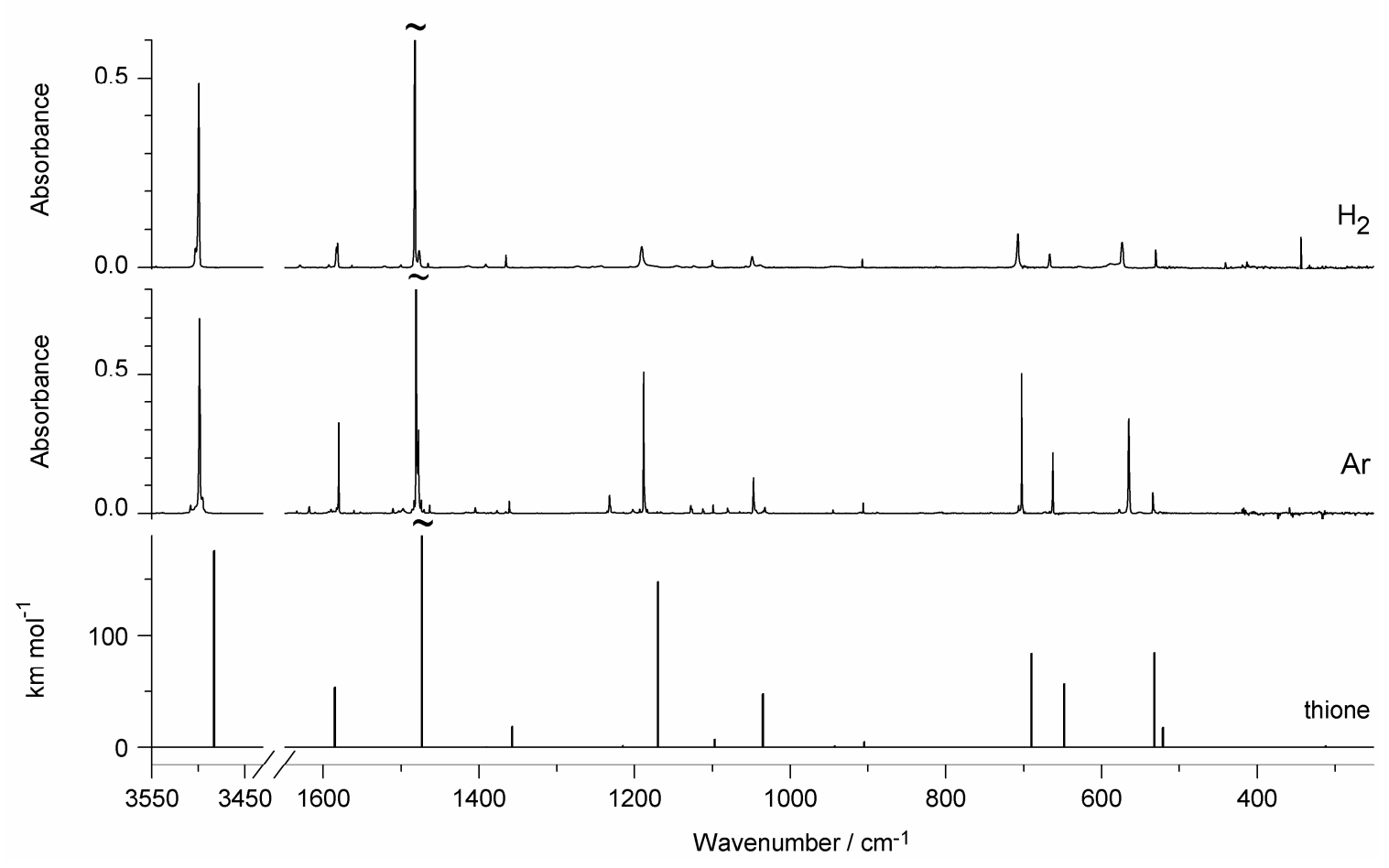

Figure S4. Fragments of the IR spectra of 2-thioimidazole monomers isolated in: (upper panel) $\mathrm{n}-\mathrm{H}_{2}$ and (middle panel) Ar matrices. The spectra are juxtaposed with the theoretical spectrum (bottom panel) calculated at DFT(B3LYP)/6-311++G(2d,p) level for the thione tautomer of the compound. The theoretical wavenumbers, calculated within the harmonic approximation, higher than $3000 \mathrm{~cm}^{-1}$ were multiplied by 0.95 , whereas the wavenumbers lower than $3000 \mathrm{~cm}^{-1}$ were multiplied by 0.98 . 
Table S1. Approximate assignment of the absorption bands, observed in the IR spectrum of monomers of 2-thioimidazole isolated in $\mathrm{Ar}$ and $\mathrm{n}-\mathrm{H}_{2}$ matrices, to the normal modes calculated, at the DFT(B3LYP)/6-311++G(2d,p) level of theory, for the thione tautomer of the compound.

\begin{tabular}{|c|c|c|c|c|c|c|}
\hline \multicolumn{4}{|c|}{ Experiment } & \multicolumn{3}{|c|}{ Calculation } \\
\hline Ar matrix & & $\mathrm{n}-\mathrm{H}_{2}$ matrix & & $\begin{array}{l}\mathrm{DFT}(\mathrm{I} \\
/ 6-311\end{array}$ & $2 \mathrm{~d}, \mathrm{p})$ & $\begin{array}{l}\text { Approximate } \\
\text { description }\end{array}$ \\
\hline $\begin{array}{c}\nabla \\
\mathrm{cm}^{-1}\end{array}$ & $\begin{array}{c}I \\
\text { rel. }\end{array}$ & $\begin{array}{c}\nabla \\
\mathrm{cm}^{-1}\end{array}$ & $\begin{array}{c}I \\
\text { rel. }\end{array}$ & $\begin{array}{r}\sigma^{\mathrm{a}} \\
\mathrm{cm}^{-1}\end{array}$ & $\begin{array}{c}A^{\text {th }} \\
\mathrm{km} \mathrm{mol}^{-1}\end{array}$ & \\
\hline$\underline{3499}, 3498 \mathrm{sh}$ & 187 & $3501 \mathrm{sh}, \underline{3499}$ & 191 & $\begin{array}{l}3485 \\
3483\end{array}$ & $\begin{array}{l}0.001 \\
176\end{array}$ & $\begin{array}{l}v \mathrm{NH} \\
v \mathrm{NH}\end{array}$ \\
\hline 3193 & 1 & 3186 & 1 & 3128 & 0.3 & $v \mathrm{CH}$ \\
\hline 3158 & 6 & 3157 & 5 & 3110 & 3 & $v \mathrm{CH}$ \\
\hline 1580 & 49 & 1583,1581 & 57 & 1585 & 53 & $v \mathrm{C}=\mathrm{C}$ \\
\hline$\underline{1481}, 1477$ & 380 & $\underline{1482}, 1477$ & 399 & 1473 & 397 & $\beta_{\mathrm{s}} \mathrm{NH}, v_{\mathrm{s}} \mathrm{CN}$ \\
\hline 1361 & 9 & 1365 & 15 & 1357 & 19 & $\beta_{\mathrm{a}} \mathrm{NH}, v_{\mathrm{a}} \mathrm{CN}$ \\
\hline 1189 & 106 & 1191 & 106 & 1170 & 148 & $v_{\mathrm{s}} \mathrm{CN}, v \mathrm{C}=\mathrm{S}$ \\
\hline 1099 & 6 & 1100 & 13 & 1097 & 7 & $v_{\mathrm{s}} \mathrm{CN}, \beta_{\mathrm{s}} \mathrm{NH}$ \\
\hline 1048 & 39 & 1049 & 55 & 1035 & 48 & $v_{\mathrm{a}} \mathrm{CN}, \beta_{\mathrm{a}} \mathrm{CH}$ \\
\hline 945 & 2 & 947 & 1 & 943 & 1 & $\beta \mathrm{R}, \beta_{\mathrm{s}} \mathrm{CH}$ \\
\hline 907 & 6 & 907 & 7 & 905 & 5 & $\beta \mathrm{R}$ \\
\hline 703 & 88 & 708 & 87 & 690 & 84 & $\gamma \mathrm{CH}$ \\
\hline 662 & 36 & 667 & 24 & 648 & 57 & $\gamma \mathrm{CH}$ \\
\hline 565 & 120 & 574 & 79 & 532 & 85 & $\gamma \mathrm{NH}$ \\
\hline 534 & 18 & 530 & 22 & 521 & 18 & $\vee \mathrm{C}=\mathrm{S}$ \\
\hline
\end{tabular}

a The theoretical wavenumbers higher than $3000 \mathrm{~cm}^{-1}$ were scaled by a factor of 0.95 , whereas those lower than $3000 \mathrm{~cm}^{-1}$ were scaled by 0.98 .

$v$ stretching, $\beta$ bending, $\tau$ torsion, $\gamma$ wagging, $\beta \mathrm{R}$ bending of the ring

$\nu_{\mathrm{s}}$ symmetric stretching, $\beta_{\mathrm{s}}$ symmetric bending,

$\nu_{\mathrm{a}}$ antisymmetric stretching, $\beta_{\mathrm{a}}$ antisymmetric bending

The strongest bands are underlined; sh - shoulder 


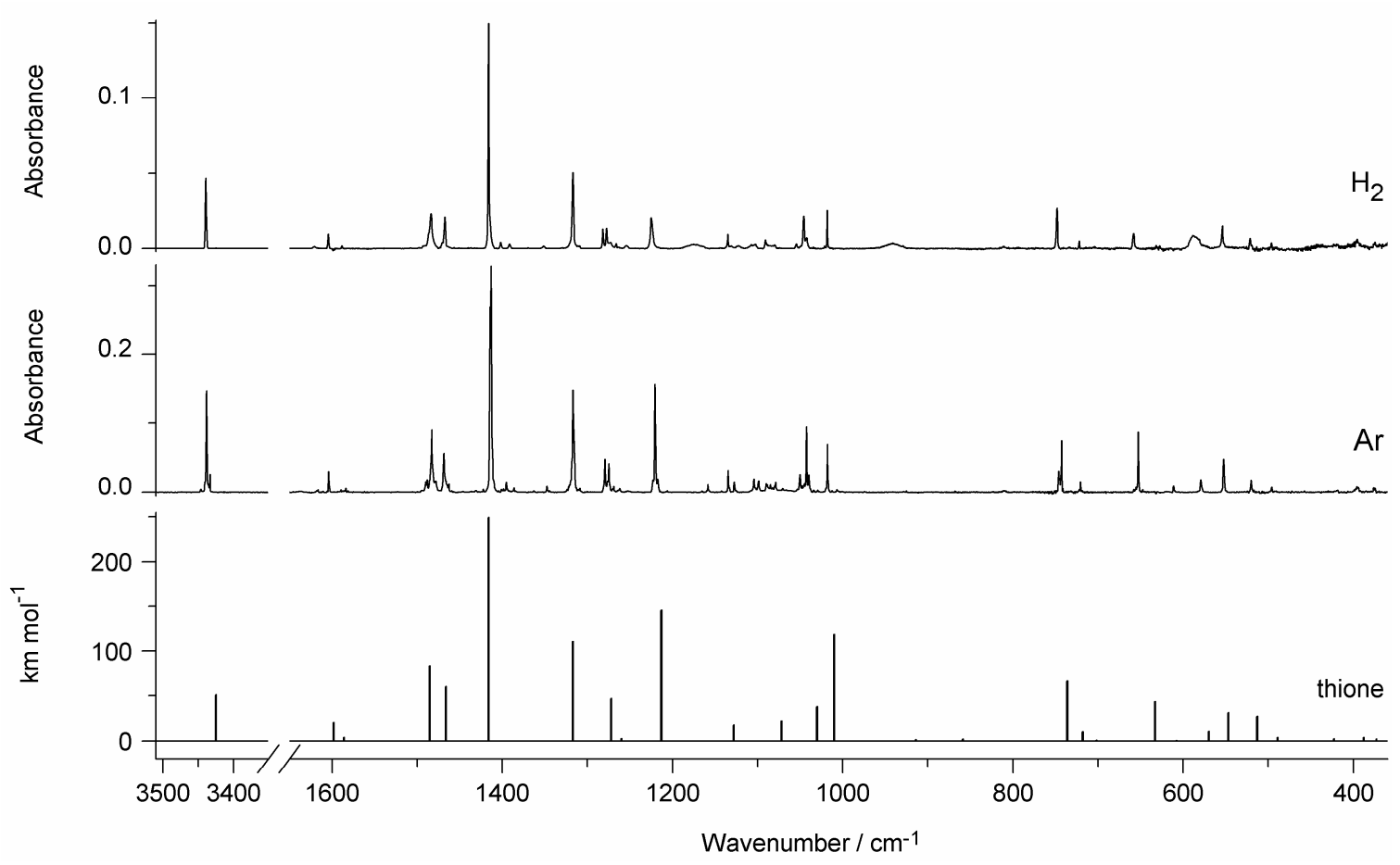

Figure S5. Fragments of the IR spectra of 2-thiobenzothiazole monomers isolated in: (upper panel) $\mathrm{n}-\mathrm{H}_{2}$ and (middle panel) Ar matrices; juxtaposed with (bottom panel) the theoretical spectrum calculated, at DFT(B3LYP)/6-311++G(2d,p) level, for the thione tautomer of the compound. The theoretical wavenumbers, calculated within the harmonic approximation, higher than $3000 \mathrm{~cm}^{-1}$ were multiplied by 0.95 , whereas the wavenumbers lower than 3000 $\mathrm{cm}^{-1}$ were multiplied by 0.98 .

2-thiobenzothiazole

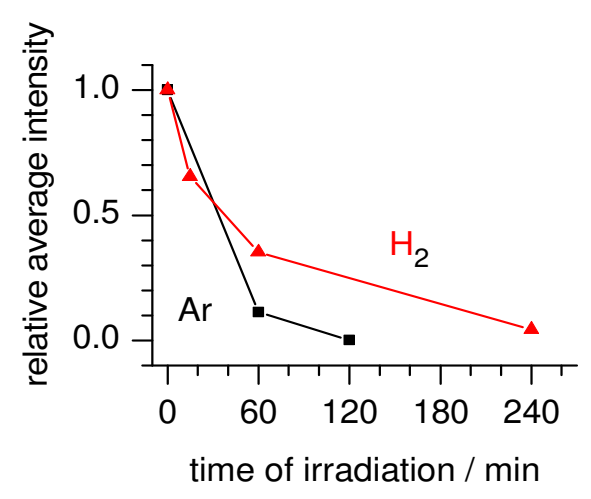

Decay of the thione tautomer during UV (305 nm) irradiation

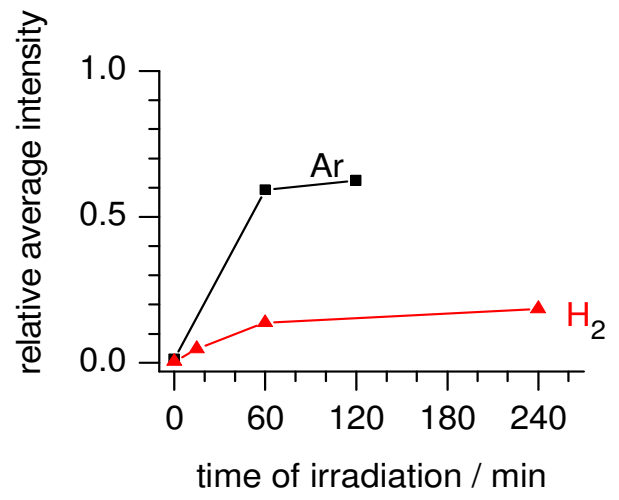

Formation of the thiol tautomer during UV (305 $\mathrm{nm}$ ) irradiation

Figure S6. The comparison of the progress of the thione $\rightarrow$ thiol phototautomeric reaction in monomers of 2-thiobenzothiazole isolated in $\mathrm{Ar}$ (black traces) and $\mathrm{n}-\mathrm{H}_{2}$ (red traces) matrices. 
Table S2. Approximate assignment of the absorption bands, observed in the IR spectrum of monomers of 2-thiobenzothiazole isolated in $\mathrm{Ar}$ and $\mathrm{n}-\mathrm{H}_{2}$ matrices, to the normal modes calculated, at the DFT(B3LYP)/6-311++G(2d,p) level of theory, for the thione tautomer of the compound.

\begin{tabular}{|c|c|c|c|c|c|c|}
\hline \multicolumn{4}{|c|}{ Experiment } & \multicolumn{3}{|c|}{ Calculation } \\
\hline \multicolumn{2}{|l|}{ Ar matrix } & \multicolumn{2}{|c|}{$\mathrm{n}-\mathrm{H}_{2}$ matrix } & \multicolumn{2}{|c|}{$\begin{array}{l}\text { DFT(B3LYP)/ } \\
6-311++G(2 d, p) \\
\end{array}$} & \multirow[t]{2}{*}{$\begin{array}{l}\text { Approximate } \\
\text { description }\end{array}$} \\
\hline $\begin{array}{c}\nabla \\
\mathrm{cm}^{-1}\end{array}$ & $\begin{array}{c}I \\
\text { rel. }\end{array}$ & $\begin{array}{c}\nabla \\
\mathrm{cm}^{-1}\end{array}$ & $\begin{array}{c}I \\
r e l\end{array}$ & $\begin{array}{c}\nabla^{\mathrm{a}} \\
\mathrm{cm}^{-1}\end{array}$ & $\begin{array}{c}A^{\text {th }} \\
\mathrm{km} \mathrm{mol}^{-1}\end{array}$ & \\
\hline$\underline{3438}, 3433$ & 99 & 3439 & 85 & 3425 & 51 & $v \mathrm{NH}$ \\
\hline 1604 & 12 & 1604 & 15 & 1598 & 20 & $\vee \mathrm{CC}, v \mathrm{CN}$ \\
\hline 1583 & 3 & 1588 & 3 & 1586 & 4 & $\vee C C$ \\
\hline 1483 & 93 & 1484 & 111 & 1485 & 84 & $\beta \mathrm{NH}, \beta \mathrm{CH}$ \\
\hline 1469 & 56 & 1467 & 54 & 1466 & 60 & $\beta \mathrm{CH}, v \mathrm{CC}$ \\
\hline $1414, \underline{1413}$ & 284 & 1416 & 275 & 1416 & 249 & $\beta \mathrm{NH}, \beta \mathrm{CH}$ \\
\hline 1317 & 137 & 1317 & 133 & 1317 & 111 & $v \mathrm{CC}, \beta \mathrm{CH}$ \\
\hline 1280 & 29 & 1282 & 24 & 1272 & 47 & $\beta \mathrm{CH}$ \\
\hline 1275 & 25 & 1277 & 32 & 1260 & 3 & $\nu \mathrm{CN}, \beta \mathrm{CH}$ \\
\hline 1221 & 98 & 1225 & 80 & 1213 & 145 & $\beta \mathrm{NH}, v \mathrm{CN}$ \\
\hline$\underline{1135}, 1127$ & 14 & 1135 & 17 & 1128 & 18 & $\beta \mathrm{CH}$ \\
\hline $\begin{array}{l}1104,1099,1089 \\
1085,1079\end{array}$ & 36 & 1091,1080 & 40 & 1072 & 22 & $\beta \mathrm{R}, \nu \mathrm{C}-\mathrm{S}$ \\
\hline $1050,1043,1040$ & 80 & $1055, \underline{1046}, 1043$ & 72 & 1030 & 38 & $\beta \mathrm{CH}$ \\
\hline 1018 & 30 & 1019 & 31 & 1010 & 119 & $v \mathrm{C}-\mathrm{S}, v \mathrm{C}=\mathrm{S}, \beta \mathrm{R}$ \\
\hline 925 & 1 & 929 & 1 & 914 & 1 & $\gamma \mathrm{CH}$ \\
\hline 868 & 2 & & & 859 & 2 & $\beta \mathrm{R}, \nu \mathrm{CN}$ \\
\hline 746,743 & 46 & 748 & 58 & 736 & 66 & $\gamma \mathrm{CH}$ \\
\hline 721 & 7 & 722 & 6 & 718 & 10 & $\gamma \mathrm{CH}, \tau \mathrm{R}$ \\
\hline 653 & 34 & 659 & 27 & 633 & 43 & $v \mathrm{C}-\mathrm{S}, \beta \mathrm{R}$ \\
\hline 612 & 4 & & & 608 & 1 & $\beta \mathrm{R}, \nu \mathrm{C}-\mathrm{S}$ \\
\hline 580 & 12 & & & 570 & 11 & $\tau \mathrm{r}, \gamma \mathrm{NH}$ \\
\hline 553 & 28 & 554 & 47 & 547 & 31 & $\gamma \mathrm{NH}, \tau \mathrm{R}$ \\
\hline 520 & 11 & 522 & 15 & 513 & 27 & $\gamma \mathrm{NH}$ \\
\hline 496 & 3 & 496 & 7 & 489 & 4 & $\beta \mathrm{r}, \boldsymbol{v} \mathrm{C}-\mathrm{S}$ \\
\hline 396 & 10 & 396 & 17 & 388 & 4 & $\beta r, v C=S$ \\
\hline 376 & 4 & 376 & 6 & 373 & 2 & $\beta \mathrm{r}, \beta \mathrm{R}, \beta \mathrm{C}=\mathrm{S}$ \\
\hline
\end{tabular}


Table S2. (continuation)

${ }^{a}$ The theoretical wavenumbers higher than $3000 \mathrm{~cm}^{-1}$ were scaled by a factor of 0.95 , whereas those lower than $3000 \mathrm{~cm}^{-1}$ were scaled by 0.98 .

$v$ stretching, $\beta$ bending, $\tau$ torsion, $\gamma$ wagging,

$\beta \mathrm{R}$ bending of the six-membered ring, $\beta \mathrm{r}$ bending of the five-membered ring The strongest bands are underlined; sh - shoulder 
Table S3. Structures of the tautomeric forms of the studied compounds and the height of the barrier for the thione $\rightarrow$ thiol, oxo $\rightarrow$ hydroxy or $\mathrm{N}(1) \mathrm{H} \rightarrow \mathrm{N}(7) \mathrm{H}$ transformation, calculated at the DFT(B3LYP)/6-311++G(2d,p) level and at the MP2/6-311++G(2d,p) level.

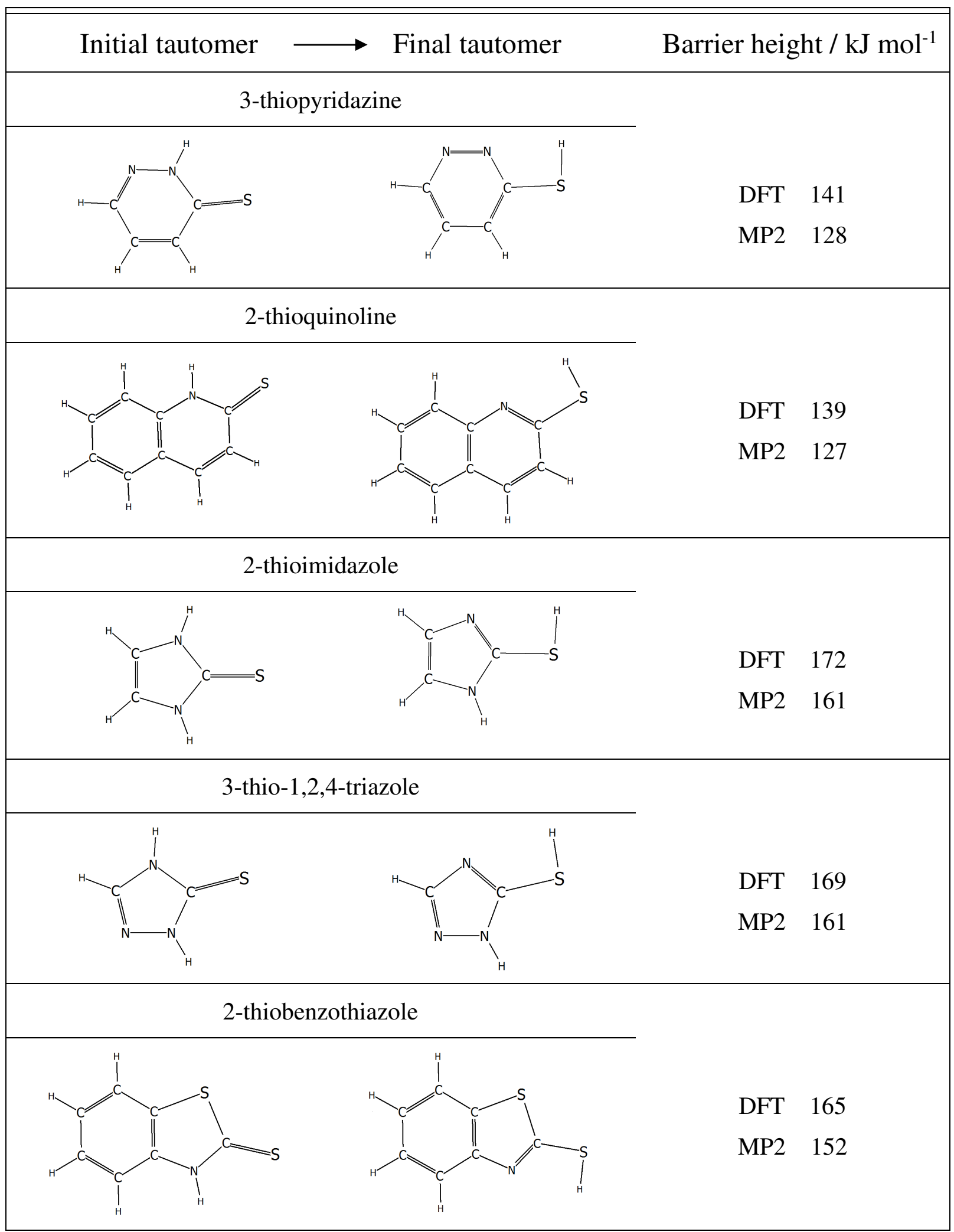




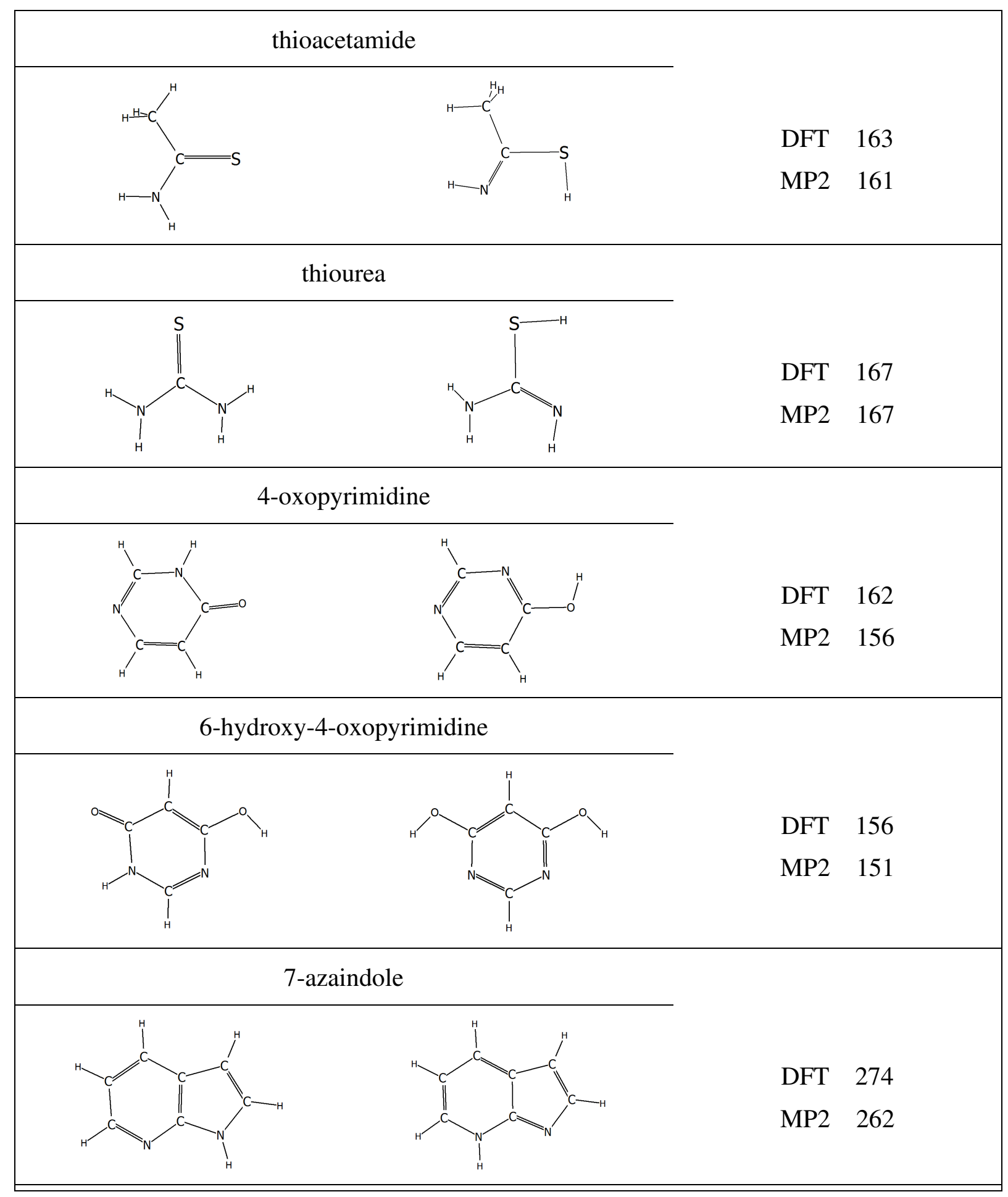

